Article

\title{
Polyphenolic Compounds Analysis of Old and New Apple Cultivars and Contribution of Polyphenolic Profile to the In Vitro Antioxidant Capacity
}

\author{
Josephine Kschonsek, Theresa Wolfram, Annette Stöckl and Volker Böhm * \\ Institute of Nutrition, Friedrich Schiller University Jena, Dornburger Straße 25-29, 07743 Jena, Germany; \\ Josephine.Kschonsek@uni-jena.de (J.K.); resi.leipzig@googlemail.com (T.W.); st_annette@gmx.de (A.S.) \\ * Correspondence: Volker.Boehm@uni-jena.de; Tel.: +49-3641-949633
}

Received: 6 December 2017; Accepted: 19 January 2018; Published: 24 January 2018

\begin{abstract}
Polyphenols are antioxidant ingredients in apples and are related to human health because of their free radical scavenging activities. The polyphenolic profiles of old and new apple cultivars $(n=15)$ were analysed using high-performance liquid chromatography (HPLC) with diode array detection (DAD). The in vitro antioxidant capacity was determined by total phenolic content (TPC) assay, hydrophilic trolox equivalent antioxidant capacity (H-TEAC) assay and hydrophilic oxygen radical absorbance (H-ORAC) assay. Twenty polyphenolic compounds were identified in all investigated apples by HPLC analysis. Quercetin glycosides $(203 \pm 108 \mathrm{mg} / 100 \mathrm{~g})$ were the main polyphenols in the peel and phenolic acids $(10 \pm 5 \mathrm{mg} / 100 \mathrm{~g})$ in the flesh. The calculated relative contribution of single compounds indicated flavonols (peel) and vitamin C (flesh) as the major contributors to the antioxidant capacity, in all cultivars investigated. The polyphenolic content (HPLC data) of the flesh differed significantly between old $(29 \pm 7 \mathrm{mg} / 100 \mathrm{~g})$ and new $(13 \pm 4 \mathrm{mg} / 100 \mathrm{~g})$ cultivars, and the antioxidant capacity of old apple cultivars was up to $30 \%$ stronger compared to new ones.
\end{abstract}

Keywords: apple polyphenols; HPLC-DAD; Folin-Ciocalteu; TEAC; ORAC; vitamin C; relative antioxidant activity

\section{Introduction}

Apples (Malus domestica) have a growing scientific interest because many investigations have demonstrated their beneficial effects on human health. Through a variety of antioxidant ingredients, apples have been associated with reduced risks of degenerative and cardiovascular diseases, which are considered to be caused by oxidative stress, especially by free radicals and reactive oxygen species (ROS) [1]. Antioxidants have become even more a focus of research due to increased exposure to ROS.

Polyphenols are the most abundant antioxidants in the human diet and the major part of antioxidants in apples, rather than essential nutrients such as vitamin $C[2,3]$. Apples are one of the most important fruit sources of dietary polyphenolic compounds in the Western diet, due to the fact that they are consumed widely and are available throughout the year [4]. In Germany, they are the most popular type of fruit with an annual consumption of $25.9 \mathrm{~kg}$ per person [5]. Polyphenols represent a group of secondary metabolites with aromatic ring(s) bearing one or more hydroxyl moieties [6]. The large number of conjugated double bonds and hydroxyl groups is responsible for their antioxidant activity (AOA) [3,7]. There are five major groups of polyphenolic compounds found in apples: flavanols (catechin, epicatechin and procyanidins), phenolic acids (mainly chlorogenic acid), dihydrochalcones (phloretin glycosides), flavonols (quercetin glycosides) and anthocyanins (cyanidin) $[8,9]$. Various reports indicate that the polyphenolic profile and content as well as the 
antioxidant capacity (AOC) in apples are affected by different variables, such as cultivar, tissue zones, harvest time, geographic location and storage conditions [10-12].

In recent decades, new apple cultivars, such as Braeburn, Elstar, Golden Delicious, Granny Smith and Jonagold have become more popular among consumers in Germany and Western Europe, resulting in a gradual decrease of the cultivation of old cultivars. New cultivars are said to have a lower content of polyphenols. The contents of polyphenolic compounds of new cultivars were reduced by breeding due to the astringent taste and rapid enzymatic browning. Therefore, we hypothesize that the content of polyphenols and consequently the AOC of old apple cultivars are higher compared to new cultivars. The comparison of the polyphenol content as well as the occurrence and distribution of the main polyphenolic classes is barely reported for old and new apple cultivars. There is just one investigation that distinguished between old and new apple cultivars, but without separately analysing peel and flesh [13]. Apples provide a mixture of bioactive compounds, but the total phenolic or total flavonoid content often does not directly reflect the AOC [7]. There are some studies that have investigated the polyphenolic content of apple cultivars, using spectrophotometric assays or HPLC analysis. However, there is limited information about the relative contribution of each polyphenolic compound to the AOC because the number of standards used is restricted, especially with regard to the procyanidins and quercetin glycosides. In the present study, the contents of polyphenolic compounds in peel and flesh of different old and new apple cultivars were determined by using HPLC-DAD. Additionally, the in vitro AOC was measured using total phenolic content (TPC) assay, hydrophilic trolox equivalent antioxidant capacity (H-TEAC) assay and hydrophilic oxygen radical absorbance capacity (H-ORAC) assay. AOA data of 20 polyphenols and of vitamin $\mathrm{C}$ were determined and used to calculate the contribution of these antioxidants to the AOC.

\section{Materials and Methods}

\subsection{Chemicals}

Methanol and ethanol were from VWR (Darmstadt, Germany) and were like all other solvents used of HPLC grade. Trolox, 2,2'-azinobis-(3-ethylbenzothiazoline-6-sulphonic acid) diammonium salt (ABTS), Folin-Ciocalteu reagent, quercetin, (-)-epicatechin, procyanidin B1, procyanidin $\mathrm{B} 2$, procyanidin $\mathrm{C} 1$, p-coumaric acid, trans-cinnamic acid and phloridzin dihydrate were from Sigma-Aldrich (Taufkirchen, Germany). Gallic acid, (+)-catechin, chlorogenic acid, ferulic acid, coffeic acid, rutin trihydrate and acetic acid were purchased from Carl Roth (Karlsruhe, Germany). Avicularin was used from Phytolab (Vestenbergsgreuth, Germany). Protocatechuic acid, hyperoside, isoquercitrin, quercitrin and procyanidin A2 were from Extrasynthese (Genay, France). Reynoutrin was purchased from Carbosynth Limited (Berkshire, UK). 2,2'-Azobis(2-amidinopropane) dihydrochloride (AAPH) was from Fisher Scientific (Nidderau, Germany). HPLC grade water (18 M $\Omega$ ) was prepared using a MicroPure purification system (Thermo Electron LED GmbH, Niederelbert, Germany). Sodium hydroxide, hydrochloric acid (Merck, Darmstadt, Germany), meta-phosphoric acid (Sigma-Aldrich) and all other chemicals were of analytical grade.

\subsection{Sample Details and Preparation}

Fifteen different apple cultivars were chosen for the investigation of polyphenolic compounds, vitamin C and AOC, including ten old apple cultivars (Berlepsch, Cox Orange, Dülmener Rosenapfel, Goldparmäne, Gravensteiner, James Grieve, Jonathan, Oldenburger, Ontario and Roter Boskoop) and five new apple cultivars (Braeburn, Elstar, Golden Delicious, Granny Smith and Jonagold). The new cultivars were picked at maturity, during harvest season in 2015, from a local market in Jena, Germany, and the old cultivars were from a private garden (Bad Blankenburg, Germany: $50^{\circ} \mathrm{N}-11^{\circ} \mathrm{E}$ ). A pomologist authenticated the apple cultivars. One tree from each old cultivar was used for the gathering of fruits for the study. In total, three to five $\mathrm{kg}$ were harvested, depending on the size of the tree. The apples were picked from all sides of the tree. Fruit samples were peeled (2-3 mm thickness) 
and cored. The peel and flesh samples were homogenised separately, using a knife mill Grindomix GM 200 (Retsch, Haan, Germany), and stored at $-25^{\circ} \mathrm{C}$ until use. For all analyses (polyphenolic compounds, vitamin $\mathrm{C}$ and $\mathrm{AOC}$ ), the peel and flesh samples were lyophilised.

\subsection{Food Extraction}

\subsubsection{Polyphenolic Compounds Analysis}

Each apple cultivar was weighed into a $50 \mathrm{~mL}$ Falcon tube. For the determination of content of polyphenols, freeze-dried samples of apple peel $(0.5 \pm 0.05 \mathrm{~g})$ and apple flesh $(2.0 \pm 0.05 \mathrm{~g})$ were used. Samples were hydrolysed, using a method slightly modified from [14], involving the stepwise addition of hydrochloric acid $(1 \mathrm{M})$, followed by addition of sodium hydroxide solution in $75 \%$ methanol $(2.0 \mathrm{M})$ and meta-phosphoric acid $(0.75 \mathrm{M})$. A volume of $2 \mathrm{~mL}$ (apple peel) or $4 \mathrm{~mL}$ (apple flesh), respectively, was used of each solvent. All steps were accompanied by shaking (30 s) and heating in a water bath $\left(30 \mathrm{~min}, 37^{\circ} \mathrm{C}\right)$. After hydrolysis, the samples were centrifuged $(5 \mathrm{~min}$, $3000 \times g)(5702 \mathrm{R}$, Eppendorf, Hamburg, Germany). The supernatants were collected in $250 \mathrm{~mL}$ round-bottomed flasks. The remaining residues were extracted with $20 \mathrm{~mL}$ methanol/water $(70 / 30$, $v / v)$, using an ultrasonic bath $\left(20 \mathrm{~min}, \leq 40^{\circ} \mathrm{C}\right)$. After centrifugation $(5 \mathrm{~min}, 3000 \times g)$, the supernatants were collected. The extraction was repeated twice, while the time of ultrasonic treatment was changed to $10 \mathrm{~min}$ (in both extractions) and the volume of methanol/water to $10 \mathrm{~mL}$ (only in the last extraction). The extraction procedure was performed according to a modified method from [15]. The supernatants of hydrolysis and the combined extracts were mixed and rotary-evaporated, under reduced pressure, at $35^{\circ} \mathrm{C}$, to a small volume. The dried residues were dissolved in methanol/water $(70 / 30, v / v, 5 \mathrm{~mL})$. After centrifugation $(5 \mathrm{~min}, 19,000 \times g)$, the samples were used for HPLC analysis.

\subsubsection{Antioxidant Capacity (AOC) Assays}

Each apple cultivar was weighed into a $15 \mathrm{~mL}$ Falcon tube. For the AOC assays freeze-dried samples of apple peel $(0.1 \pm 0.01 \mathrm{~g})$ and apple flesh $(0.4 \pm 0.05 \mathrm{~g})$ were used. Samples were hydrolysed, as described in the previous Section 2.3.1, except that the volume of each solvent was decreased five-fold. After hydrolysis, the samples were centrifuged ( $5 \mathrm{~min}, 3000 \times \mathrm{g}$ ) (5702 R, Eppendorf, Hamburg, Germany) and the supernatants were collected in $10 \mathrm{~mL}$ volumetric flasks. The residues were extracted with $2 \mathrm{~mL}$ methanol/water $(70 / 30, v / v)$ by shaking for $30 \mathrm{~min}$. After centrifugation ( $5 \mathrm{~min}$, $3000 \times g)$, the supernatants were collected and the extraction was repeated twice. The supernatants from hydrolysis and the combined extracts were mixed and used for AOC assays.

\subsection{HPLC Analysis of Polyphenols}

The polyphenolic composition was analysed using a diode array detector (L-7450A, Merck Hitachi, Darmstadt, Germany) according to the method from [16]. The column was a reversed-phase Luna C18 column ( $250 \mathrm{~mm} \times 4.6 \mathrm{~mm}$, particle size $5 \mu \mathrm{m}$, Phenomenex, Aschaffenburg, Germany) and was heated to $30^{\circ} \mathrm{C}$. An injection volume of $50 \mu \mathrm{L}$ was used. The binary mobile phase consisted of $0.5 \%(v / v)$ acetic acid in water (solvent A) and methanol (solvent B), pumped at a flow rate of $0.8 \mathrm{~mL} / \mathrm{min}$, for a total run time of $160 \mathrm{~min}$. Elution was performed using a gradient program: 0-2 min, 0\% B isocratic; $2-6 \mathrm{~min}$, linear gradient from $0 \%$ to $15 \% \mathrm{~B} ; 6-12 \mathrm{~min}, 15 \% \mathrm{~B}$ isocratic; $12-17 \mathrm{~min}$, linear gradient from $15 \%$ to $20 \% \mathrm{~B} ; 17-35 \mathrm{~min}, 20 \%$ B isocratic; $35-90 \mathrm{~min}$, linear gradient from $20 \%$ to $35 \% \mathrm{~B} ; 90-132 \mathrm{~min}, 35 \% \mathrm{~B}$ isocratic, $132-150 \mathrm{~min}$, linear gradient from $35 \%$ to $80 \% \mathrm{~B}, 150-160$ min linear gradient from $80 \%$ to $0 \%$ B. The detector was set at 254,280 and $320 \mathrm{~nm}$ for simultaneous monitoring of the different groups of polyphenols. The identification was performed by comparing retention times and DAD absorbance spectra with external standards (Table 1). Polyphenolic compound contents were quantified with a 7-point calibration curve of external standards. Linearity was given over the entire 7-point calibration curve. The limits of detection (LOD) and limits of quantification (LOQ) of the polyphenols were determined using the baseline noise signals in chromatograms of five solvent injections (Table S1). 
Table 1. Characterization (retention time $\left[t_{R}\right]$, absorption maximum $\left[\lambda_{\max }\right]$ ) of 20 polyphenols of apples used as reference compounds in HPLC-DAD.

\begin{tabular}{|c|c|c|c|c|c|}
\hline Group of Polyphenols & Phenolic Compound & Synonyms & $t_{R}[\min ]$ & $\lambda_{\max }[\mathrm{nm}]$ & $\lambda[\mathrm{nm}]$ \\
\hline \multirow{6}{*}{ Flavanols } & Procyanidin B1 & & 21.09 & 281 & 280 \\
\hline & $(+)$-Catechin & & 25.71 & 281 & 280 \\
\hline & Procyanidin B2 & & 29.04 & 281 & 280 \\
\hline & Procyanidin C1 & & 39.87 & 275 & 280 \\
\hline & $(-)$-Epicatechin & & 43.11 & 280 & 280 \\
\hline & Procyanidin A2 & & 68.85 & 280 & 280 \\
\hline \multirow{6}{*}{ Phenolic acids } & Gallic acid & \multirow{6}{*}{ Chlorogenic acid } & 12.64 & 272 & 280 \\
\hline & Protocatechuic acid & & 18.80 & 261,298 & 254 \\
\hline & 5-O-Caffeoylquinic acid & & 31.12 & 326 & 320 \\
\hline & Caffeic acid & & 36.05 & 324 & 320 \\
\hline & p-Coumaric acid & & 57.10 & 310 & 320 \\
\hline & Ferulic acid & & 66.15 & 324 & 320 \\
\hline Dihydrochalcones & Phloretin-2-O- $\beta$-glucoside & Phloridzin * & 106.84 & 287 & 280 \\
\hline \multirow{7}{*}{ Flavonols } & Quercetin-3-O-galactoside & Hyperoside & 94.19 & 259,348 & 254 \\
\hline & Quercetin-3-O-glucoside & Isoquercitrin & 96.96 & 259,351 & 254 \\
\hline & Quercetin-3-O-rutinoside & Rutin* & 97.68 & 259,348 & 254 \\
\hline & Quercetin-3-O-xyloside & Reynoutrin & 101.23 & 260,348 & 254 \\
\hline & Quercetin-3-O-arabinoside & Avicularin & 112.03 & 260,347 & 254 \\
\hline & Quercetin-3-O-rhamnoside & Quercitrin & 116.37 & 260,347 & 254 \\
\hline & Quercetin & & 145.33 & 256,372 & 254 \\
\hline
\end{tabular}

* Phloridzin as Phloridzin dehydrate; Rutin as Rutin trihydrate; $\lambda$ : wavelength used in HPLC-DAD.

\subsection{Antioxidant Capacity (AOC)}

The AOC assays were performed by using clear 96-well microplates (Kisker Biotech, Steinfurt, Germany) and a microplate reader FluoStar Optima (BMG Labtech, Offenburg, Germany), in accordance with [17].

\subsubsection{Total Phenolic Content (TPC) Assay}

The TPC was evaluated by using the Folin-Ciocalteu method [18]. Thirty microliters of methanol/water $(70 / 30, v / v)$ extract were mixed with $150 \mu \mathrm{L}$ 1:10 diluted Folin-Ciocalteu reagent and $120 \mu \mathrm{L}$ sodium carbonate solution $(75 \mathrm{~g} / \mathrm{L})$ in wells of a 96-well microplate. After $2 \mathrm{~h}$ in darkness, at room temperature, the absorbance was measured at $740 \mathrm{~nm}$ in the microplate reader, at $30{ }^{\circ} \mathrm{C}$. Gallic acid monohydrate (8.51-170.12 mg/L) was used as the standard for calibration and construction of a linear regression line and water acted as the blank. The TPC is expressed as gallic acid equivalents (GAE) in $\mathrm{mg} / 100 \mathrm{~g}$.

\subsubsection{Hydrophilic Trolox Equivalent Antioxidant Capacity (H-TEAC) Assay}

The H-TEAC assay was performed using ABTS radical cation $\left(\right.$ ABTS $\left.^{\bullet+}\right)$ [19]. This stable radical cation was formed by mixing $10 \mathrm{~mL}$ ABTS solution $(7 \mathrm{mM})$ with $10 \mathrm{~mL}$ potassium peroxodisulfate solution $(2.45 \mathrm{mM})$. After $24 \mathrm{~h}$ at room temperature (darkness), the $\mathrm{ABTS}^{\bullet+}$ stock solution was ready to use. The $\mathrm{ABTS}^{\bullet+}$ working solution was prepared freshly each day by diluting the $\mathrm{ABTS}^{\bullet+}$ stock solution with phosphate buffer $(75 \mathrm{mM}, \mathrm{pH} 7.4)$ to an absorbance of $0.70 \pm 0.05$ at $730 \mathrm{~nm}$. Twenty microliters of methanol/water $(70 / 30, v / v)$ extract were mixed with $200 \mathrm{~mL} \mathrm{ABTS}{ }^{\bullet+}$ working solution in a 96-well microplate. The decrease in absorbance at $730 \mathrm{~nm}$, at $30^{\circ} \mathrm{C}$, was measured photometrically. Trolox solutions $(12.5-250 \mu \mathrm{M})$ were used for constructing a regression line and water acted as blank. The AOC is expressed as trolox equivalents (TE) in mmol/100 $\mathrm{g}$.

\subsubsection{Hydrophilic Oxygen Radical Absorbance Capacity (H-ORAC) Assay}

The H-ORAC assay was evaluated using fluorescein and AAPH [20]. The fluorescein working solution $(1.2 \mu \mathrm{M})$ was prepared freshly each day by diluting the fluorescein stock solution $(0.12 \mathrm{mM}$, stored in fridge) 1:100 with phosphate buffer $(75 \mathrm{mM}, \mathrm{pH} 7.4)$. Ten microliters of methanol/water 
$(70 / 30, v / v)$ extract were mixed with $25 \mu \mathrm{L}$ fluorescein working solution and $100 \mu \mathrm{L}$ phosphate buffer, in microplate wells. Afterwards, the 96-well plate was pre-heated for $10 \mathrm{~min}$ at $37{ }^{\circ} \mathrm{C}$. Following the addition of $150 \mu \mathrm{L}$ of freshly prepared and ice-cooled AAPH solution (129 mM) in phosphate buffer, the reaction started, and the fluorescence intensity was measured each minute, for $4 \mathrm{~h}$, at $37^{\circ} \mathrm{C}$. Fluorescence filters of $490 \mathrm{~nm}$ (excitation) and $520 \mathrm{~nm}$ (emission) were used in the microplate reader. Water acted as a blank and trolox standard solutions $(0.1-2.0 \mathrm{mM})$ were used for calibration. Additionally, a negative control (water) was used for controlling the photostability of fluorescein. Therefore, $150 \mu \mathrm{L}$ of phosphate buffer was utilised instead of AAPH solution. The calculation of the $\mathrm{H}-\mathrm{ORAC}$ assay can be seen in the publication by [17]. The AOC is expressed as trolox equivalents (TE) in $\mathrm{mmol} / 100 \mathrm{~g}$.

\subsection{Vitamin C Analysis}

The vitamin $C$ analysis was performed in accordance with [21]. Each apple cultivar was weighed into a screwed glass tube. Freeze-dried samples of apple peel $(0.1 \pm 0.01 \mathrm{~g})$ and apple flesh $(0.4 \pm 0.05 \mathrm{~g})$ were used. Samples were extracted three times with $5 \mathrm{~mL}$ meta-phosphoric acid $(0.46 \mathrm{M})$ by shaking for $1 \mathrm{~min}$. After each extraction, the samples were centrifuged $(5 \mathrm{~min}, 3000 \times \mathrm{g})$. The supernatants were collected in $20 \mathrm{~mL}$ volumetric flasks. Two hundred microliters of each sample, $200 \mu \mathrm{L}$ of calibration solution (5.7-567.8 $\mu \mathrm{M}$, respectively) and $200 \mu \mathrm{L}$ of distilled water (blank) were mixed with $300 \mu \mathrm{L}$ trichloroacetic acid $(0.31 \mathrm{M})$ and centrifuged $(5 \mathrm{~min}, 17,000 \times \mathrm{g})$. Three hundred microliters of the supernatants were mixed with $100 \mu \mathrm{L}$ DNP reagent (one volume of thiourea solution $(0.83 \mathrm{M}$ in distilled water), one volume of copper sulphate solution ( $24 \mathrm{mM}$ in distilled water) and 20 volumes of 2,4-dinitrophenylhydrazine solution ( $0.11 \mathrm{M}$ in $4.5 \mathrm{M}$ sulfuric acid). The mixture was heated in a thermomixer $\left(1 \mathrm{~h}, 60^{\circ} \mathrm{C}\right)$. The samples were cooled in an ice bath for $5 \mathrm{~min}$. Afterwards, $400 \mu \mathrm{L}$ sulfuric acid $(8.56 \mathrm{M})$ was added and mixed. The samples were placed into darkness for $20 \mathrm{~min}$. Finally, the samples were decanted into semi-micro cuvettes and measured using a photometer at $520 \mathrm{~nm}$.

\subsection{Statistical Analysis}

All analyses were done in triplicate. The data are expressed as mean \pm standard deviation (SD) and were analysed using SPSS procedures (version 22.0, Statistical Package for the Social Sciences, Chicago, IL, USA). $p$-Values $<0.05$ were considered significant. The homogeneity of variances for all data was assumed by Levene's test. The one factorial analysis of variance (ANOVA) was used followed by the Student-Newmann-Keuls (S-N-K) procedure for assessing differences between all 15 apple cultivars. The unpaired $t$-test was used to statistically compare the average out of all ten old cultivars and the average out of all five new cultivars. Correlations were tested by using the Pearson procedure, in which the $p$-value was considered to be significant at $p<0.01$.

\section{Results and Discussion}

\subsection{Quantification of Polyphenolic Compounds and Vitamin C}

In the apples investigated, 20 polyphenolic compounds of four sub-classes (flavanols, phenolic acids, dihydrochalcones and flavonols) were identified by using retention times and absorption maxima of reference compounds (Table 1). The types of polyphenolic compounds detected in the apple cultivars were similar to previous studies, including the closely related quercetin glycosides that are often difficult to separate $[13,15]$.

As shown in Tables 2 and 3, the content of polyphenolic compounds varied greatly between apple peel and flesh. The total polyphenols determined by HPLC ranged from $99.6 \pm 5.4$ to $495.3 \pm 44.0 \mathrm{mg} / 100 \mathrm{~g}$ in the peel, whereas the flesh had a 3.0 to 28.4 times lower content $(9.6 \pm 0.6$ to $41.6 \pm 2.3 \mathrm{mg} / 100 \mathrm{~g})$. These results are comparable with other investigations $[9,11,22,23]$. 
Table 2. Average content of vitamin C, polyphenolic compounds and antioxidant capacity values in the peel of different apple cultivars.

\begin{tabular}{|c|c|c|c|c|c|c|c|c|c|c|c|c|c|c|c|}
\hline Apple Cultivars & 1 & 2 & 3 & 4 & 5 & 6 & 7 & 8 & 9 & 10 & 11 & 12 & 13 & 14 & 15 \\
\hline vitamin C & 207.5 & 215.7 & 196.9 & 155.5 & 186.4 & 124.3 & 225.8 & 99.2 & 117.4 & 184.0 & 189.1 & 210.2 & 256.0 & 300.9 & 204.4 \\
\hline procyanidin B1 & n.d. & n.d. & 1.3 & 4.8 & n.d. & n.d. & 0.9 & n.d. & 1.8 & 1.0 & n.d. & 0.9 & n.d. & 1.3 & n.d. \\
\hline$(+)$-catechin & 2.3 & 4.9 & 2.7 & 6.8 & 9.0 & 1.5 & 3.5 & 3.4 & 3.2 & 3.0 & 8.3 & 7.4 & 11.7 & 7.4 & 3.6 \\
\hline procyanidin $B 2$ & 7.5 & 7.2 & 7.8 & 5.2 & 9.0 & 8.2 & 9.6 & 5.1 & 4.4 & 6.8 & 7.6 & 8.3 & 8.2 & 6.2 & 6.7 \\
\hline procyanidin $\mathrm{C} 1$ & 6.6 & 7.0 & 5.2 & 6.6 & 9.5 & n.d & 6.6 & 6.9 & n.d. & 5.3 & 7.7 & 7.6 & 8.3 & 8.4 & 5.9 \\
\hline (-)-epicatechin & 13.2 & 11.4 & 3.0 & 8.9 & 18.5 & 1.1 & 7.9 & 3.1 & 2.2 & 4.2 & 16.4 & 13.2 & 17.8 & 11.3 & 6.4 \\
\hline procyanidin A2 & 4.1 & 10.5 & 7.7 & 7.3 & 10.4 & 5.1 & 10.2 & 2.6 & 12.4 & 12.1 & 9.8 & 5.1 & 8.7 & 5.7 & 5.0 \\
\hline total flavanols & 33.7 & 41.0 & 27.7 & 39.5 & 56.4 & 15.8 & 38.7 & 21.0 & 23.9 & 32.3 & 49.8 & 42.4 & 54.7 & 40.4 & 27.5 \\
\hline SD & \pm 4.2 & \pm 2.7 & \pm 2.7 & \pm 1.5 & \pm 4.1 & \pm 3.3 & \pm 3.6 & \pm 1.8 & \pm 4.4 & \pm 3.8 & \pm 3.7 & \pm 4.1 & \pm 3.6 & \pm 3.3 & \pm 1.3 \\
\hline gallic acid & 4.3 & 3.9 & 3.8 & 4.9 & 3.8 & 4.0 & 7.2 & 3.5 & 4.8 & 4.7 & 4.2 & 4.8 & 4.3 & 3.9 & 3.7 \\
\hline protocatechuic acid & 1.0 & 1.3 & 1.5 & 2.3 & 1.9 & 0.6 & 1.9 & 0.8 & 1.1 & 1.3 & 2.0 & 3.8 & 1.9 & 2.4 & 2.5 \\
\hline chlorogenic acid & 18.1 & 4.9 & 4.8 & 7.0 & 5.3 & 5.9 & 5.1 & 5.2 & 3.9 & 4.0 & 6.7 & 6.1 & 7.1 & 5.5 & 5.2 \\
\hline caffeic acid & 6.6 & 1.1 & 0.4 & 11.1 & 1.2 & 0.6 & 6.2 & 0.1 & 3.2 & 0.8 & 1.2 & 1.4 & 10.4 & 3.5 & 2.2 \\
\hline p-coumaric acid & 2.6 & 1.8 & 1.7 & 5.9 & 2.3 & 1.4 & 3.5 & 1.4 & 2.4 & 1.9 & 2.0 & 2.3 & 4.1 & 1.9 & 2.2 \\
\hline ferulic acid & 1.1 & 0.4 & 1.0 & 2.3 & 0.7 & 1.3 & 2.3 & 0.7 & 0.7 & 0.7 & 1.4 & 1.4 & 1.4 & 1.0 & 1.4 \\
\hline total phenolic acids & 33.6 & 13.5 & 13.2 & 33.6 & 15.2 & 13.7 & 26.2 & 11.7 & 16.1 & 13.4 & 17.5 & 19.7 & 29.3 & 18.1 & 17.1 \\
\hline $\mathrm{SD}$ & \pm 6.5 & \pm 1.8 & \pm 1.7 & \pm 3.3 & \pm 1.7 & \pm 2.2 & \pm 2.1 & \pm 2.0 & \pm 1.6 & \pm 1.7 & \pm 2.1 & \pm 1.9 & \pm 3.4 & \pm 1.6 & \pm 1.4 \\
\hline phloridzin & 37.1 & 4.6 & 1.5 & 6.1 & 8.3 & 1.5 & 63.8 & 0.8 & 15.3 & 6.1 & 8.8 & 14.5 & 6.8 & 6.9 & 8.0 \\
\hline hyperoside & 94.7 & 103.5 & 91.2 & 44.7 & 102.8 & 18.31 & 83.4 & 28.6 & 8.0 & 80.3 & 168.1 & 190.9 & 60.2 & 189.4 & 79.3 \\
\hline isoquercitrin & 30.9 & 19.1 & 8.1 & 12.6 & 18.5 & 4.87 & 44.8 & 11.0 & 5.6 & 9.7 & 29.6 & 18.9 & 13.8 & 24.5 & 9.8 \\
\hline Rutin & 24.3 & 6.6 & 1.4 & 14.5 & 7.2 & 1.16 & 1.9 & 2.4 & 1.9 & 0.9 & 9.8 & 1.9 & 1.9 & 15.5 & 6.8 \\
\hline reynoutrin & 18.6 & 19.6 & 15.6 & 10.6 & 19.3 & 6.99 & 15.7 & 11.2 & 4.1 & 10.2 & 27.9 & 39.8 & 20.1 & 40.0 & 15.4 \\
\hline avicularin & 35.0 & 19.6 & 30.3 & 18.1 & 28.4 & 12.79 & 23.7 & 13.3 & 9.7 & 22.7 & 33.1 & 62.4 & 29.5 & 51.4 & 23.8 \\
\hline quercitrin & 36.2 & 19.7 & 18.4 & 25.5 & 17.9 & 15.94 & 15.4 & 23.4 & 15.4 & 24.0 & 50.2 & 40.6 & 17.1 & 84.1 & 20.9 \\
\hline quercetin & 17.7 & 13.5 & 16.9 & 7.6 & 13.8 & 8.54 & 12.5 & 8.8 & 7.3 & 14.0 & 22.4 & 32.5 & 12.0 & 25.1 & 9.5 \\
\hline total flavonols & 257.3 & 201.6 & 181.8 & 133.4 & 207.9 & 68.6 & 197.4 & 98.6 & 52.0 & 161.8 & 340.9 & 386.9 & 154.4 & 430.0 & 165.5 \\
\hline $\mathrm{SD}$ & \pm 26.6 & \pm 33.3 & \pm 30.1 & \pm 12.7 & \pm 32.8 & \pm 6.2 & \pm 27.7 & \pm 8.9 & \pm 4.3 & \pm 26.4 & \pm 54.0 & \pm 62.7 & \pm 18.8 & \pm 60.9 & \pm 25.3 \\
\hline total polyphenols & 361.7 & 260.8 & 224.2 & 212.5 & 287.8 & 99.6 & 326.1 & 132.1 & 107.3 & 213.5 & 416.9 & 463.5 & 245.2 & 495.3 & 218.1 \\
\hline $\mathrm{SD}$ & \pm 22.2 & \pm 22.7 & \pm 20.4 & \pm 9.7 & \pm 22.5 & \pm 5.4 & \pm 22.2 & \pm 7.8 & \pm 4.6 & \pm 17.7 & \pm 37.8 & \pm 42.9 & \pm 13.5 & \pm 44.0 & \pm 17.5 \\
\hline ТРС & 889.6 & 926.0 & 687.6 & 889.5 & 1320.4 & 521.9 & 1238.2 & 581.0 & 638.8 & 772.5 & 1224.2 & 1212.8 & 1590.5 & 1078.7 & 960.6 \\
\hline TEAC & 5.3 & 6.0 & 4.4 & 5.9 & 8.5 & 2.4 & 7.7 & 3.4 & 3.4 & 5.0 & 9.1 & 9.9 & 12.8 & 8.3 & 6.1 \\
\hline ORAC & 21.1 & 20.6 & 16.3 & 19.2 & 29.0 & 8.6 & 22.0 & 13.6 & 15.3 & 18.3 & 24.6 & 24.4 & 31.4 & 26.2 & 19.3 \\
\hline
\end{tabular}

1. Berlepsch; 2: Braeburn; 3: Cox Orange; 4: Dülmener Rosenapfel; 5: Elstar; 6: Golden Delicious; 7: Goldparmäne; 8: Granny Smith; 9: Gravensteiner; 10: James Grieve; 11: Jonagold 12: Jonathan; 13: Oldenburger; 14: Ontario; 15: Roter Boskoop; SD: standard derivation; n.d.: not detected; TPC: total phenolic content; TEAC: trolox equivalent antioxidant capacity; ORAC: oxygen radical antioxidant capacity; single compounds and total concentrations in $\mathrm{mg} / 100 \mathrm{~g}$ freeze dried material; TPC in mg GAE/100 $\mathrm{g}$ freeze dried material; TEAC and ORAC in mmol TE/100 g freeze dried material; GAE: gallic acid equivalents; TE: trolox equivalents. 
Table 3. Average content of vitamin C, polyphenolic compounds and antioxidant capacity values in the flesh of different apple cultivars.

\begin{tabular}{|c|c|c|c|c|c|c|c|c|c|c|c|c|c|c|c|}
\hline Apple Cultivars & 1 & 2 & 3 & 4 & 5 & 6 & 7 & 8 & 9 & 10 & 11 & 12 & 13 & 14 & 15 \\
\hline vitamin $C$ & 108.0 & 112.3 & 99.5 & 83.2 & 67.7 & 50.4 & 94.7 & 54.7 & 77.0 & 85.5 & 57.4 & 118.2 & 124.8 & 134.4 & 106.8 \\
\hline procyanidin B1 & 0.5 & 0.5 & n.d. & 6.8 & n.d. & 0.2 & 0.3 & n.d. & 0.8 & 0.7 & n.d. & 4.0 & 0.4 & n.d. & n.d. \\
\hline (+)-catechin & 0.8 & 0.5 & 1.4 & 1.6 & 2.5 & 0.3 & 0.8 & 1.8 & 0.3 & 1.1 & 0.5 & 4.9 & 1.0 & 1.5 & 1.3 \\
\hline procyanidin B2 & 0.9 & 1.3 & 1.9 & 2.5 & 1.8 & 1.4 & 1.7 & 1.4 & 1.4 & 1.6 & 2.0 & 2.7 & 1.9 & 2.3 & 2.0 \\
\hline procyanidin $\mathrm{C} 1$ & 1.3 & n.d. & n.d. & n.d. & n.d. & n.d. & n.d. & n.d. & n.d. & 1.3 & n.d. & 1.7 & n.d. & n.d. & n.d. \\
\hline (-)-epicatechin & 0.3 & 0.5 & 1.2 & 2.2 & 2.0 & 0.3 & 1.4 & 1.5 & 0.8 & 1.4 & 0.7 & 4.7 & 1.5 & 2.2 & 1.5 \\
\hline procyanidin $\mathrm{A} 2$ & 2.0 & 1.4 & 6.6 & 3.5 & 4.5 & 2.1 & 2.4 & 1.6 & 5.3 & 11.0 & 3.1 & 5.9 & 5.0 & 2.6 & 4.0 \\
\hline total flavanols & 5.9 & 4.2 & 11.1 & 16.6 & 10.8 & 4.4 & 6.6 & 6.3 & 8.6 & 17.1 & 6.3 & 23.8 & 9.6 & 8.6 & 8.8 \\
\hline SD & \pm 0.6 & \pm 0.5 & \pm 2.6 & \pm 2.1 & \pm 1.2 & \pm 0.9 & \pm 0.8 & \pm 0.2 & \pm 2.0 & \pm 4.0 & \pm 1.2 & \pm 1.5 & \pm 1.8 & \pm 0.5 & \pm 1.2 \\
\hline gallic acid & 1.7 & 1.6 & 1.7 & 1.6 & 1.6 & 1.9 & 2.0 & 1.4 & 1.7 & 2.2 & 1.7 & 1.9 & 1.7 & 1.6 & 1.7 \\
\hline protocatechuic acid & 0.2 & 0.1 & 0. & 0.1 & 0.1 & 0.1 & 0.1 & 0.1 & 0.1 & 0.1 & 0.1 & 0.1 & 0.2 & 0.1 & 0.3 \\
\hline chlorogenic acid & 8.4 & 2.0 & 3.2 & 10.8 & 3.6 & 1.4 & 5.8 & 1.7 & 3.3 & 3.3 & 2.1 & 4.4 & 8.3 & 7.6 & 8.6 \\
\hline caffeic acid & 5.6 & 0.6 & 1.5 & 6.8 & 1.7 & 0.5 & 1.0 & 0.5 & 0.6 & 0.7 & 0.4 & $\begin{array}{l}T .1 \\
2.2\end{array}$ & 5.0 & 3.8 & 6.0 \\
\hline p-coumaric acid & 0.7 & 0.4 & 0.6 & 0.8 & 0.6 & 0.4 & 0.7 & 0.4 & 0.7 & 0.6 & 0.5 & 0.7 & 0.9 & 0.7 & 0.8 \\
\hline ferulic acid & 0.2 & 0.1 & 0.1 & 0.2 & 0.1 & 0.1 & 0.3 & 0.1 & 0.1 & 0.2 & 0.2 & 0.1 & 0.4 & 0.1 & 0.2 \\
\hline total phenolic acids & 16.7 & 4.8 & 7.1 & 20.3 & 7.6 & 4.4 & 9.9 & 4.2 & 6.5 & 7.1 & 5.0 & 9.4 & 16.4 & 13.9 & 17.5 \\
\hline SD & \pm 3.4 & \pm 0.8 & \pm 1.2 & \pm 4.4 & \pm 1.3 & \pm 0.7 & \pm 2.1 & \pm 0.7 & \pm 1.2 & \pm 1.3 & \pm 0.8 & \pm 1.6 & \pm 3.3 & \pm 2.9 & \pm 3.5 \\
\hline phloridzin & 7.3 & 0.7 & 2.3 & 4.7 & 3.6 & 0.9 & 5.2 & 0.7 & 2.3 & 2.3 & 0.7 & 3.6 & 2.9 & 7.4 & 12.3 \\
\hline total polyphenols & 29.8 & 9.6 & 20.5 & 41.6 & 20.8 & 9.6 & 21.7 & 11.2 & 17.4 & 26.5 & 12.0 & 36.8 & 28.9 & 29.9 & 38.6 \\
\hline SD & \pm 2.8 & \pm 0.6 & \pm 1.8 & \pm 3.4 & \pm 1.4 & \pm 0.7 & \pm 2.9 & \pm 0.7 & \pm 1.5 & \pm 2.9 & \pm 1.0 & \pm 1.9 & \pm 2.5 & \pm 2.6 & \pm 3.9 \\
\hline TPC & 220.7 & 143.6 & 219.8 & 300.3 & 276.4 & 136.5 & 252.0 & 163.3 & 174.9 & 246.3 & 177.5 & 361.7 & 242.9 & 217.6 & 334.1 \\
\hline TEAC & 1.1 & 0.8 & 1.3 & 1.8 & 1.5 & 0.8 & 1.2 & 0.9 & 0.9 & 1.5 & 1.0 & 2.3 & 1.5 & 1.2 & 2.0 \\
\hline ORAC & 5.7 & 4.9 & 5.2 & 6.1 & 6.7 & 2.4 & 4.5 & 4.0 & 4.5 & 5.9 & 5.0 & 8.1 & 5.4 & 4.7 & 6.9 \\
\hline
\end{tabular}

1. Berlepsch; 2: Braeburn; 3: Cox Orange; 4: Dülmener Rosenapfel; 5: Elstar; 6: Golden Delicious; 7: Goldparmäne; 8: Granny Smith; 9: Gravensteiner; 10: James Grieve; 11: Jonagold 12: Jonathan; 13: Oldenburger; 14: Ontario; 15: Roter Boskoop; SD: standard derivation; n.d.: not detected; TPC: total phenolic content; TEAC: trolox equivalent antioxidant capacity; ORAC: oxygen radical antioxidant capacity; single compounds and total concentrations in mg/100 g freeze dried material; TPC in mg GAE/100 g freeze dried material; TEAC and ORAC in mmol TE/100 g freeze dried material; GAE: gallic acid equivalents; TE: trolox equivalents. 
The apple cultivars Ontario and Jonathan had the highest total polyphenol content in the peel and the cultivars Roter Boskoop and Dülmener Rosenapfel in the flesh. The cultivar Golden Delicious contained the significantly lowest content of total polyphenols in both peel and flesh, being in line with studies previously reported [12,24]. Furthermore, the occurrence and distribution of the main polyphenol classes differed between peel and flesh. Flavonols were the predominant group $(72.2 \%)$ in the peel, followed by flavanols $(14.7 \%)$, phenolic acids $(8.3 \%)$ and the dihydrochalcone phloridzin (4.7\%). The flavonols, which included quercetin and its glycosides, ranged from $52.0 \pm 4.3$ (Gravensteiner) to $430.0 \pm 60.9 \mathrm{mg} / 100 \mathrm{~g}$ (Ontario). A high content of quercetin was found in the peel, due to hydrolysis with $1 \mathrm{M} \mathrm{HCl}$, which efficiently released quercetin from sugar components $[25,26]$. The concentrations of the quercetin glycosides generally followed the order: hyperoside $>$ quercitrin $>$ avicularin $>$ reynoutrin $>$ isoquercitrin $>$ rutin, with interchanging of avicularin and quercitrin depending on the apple cultivar, and is almost coincident with results of other studies [27-29]. The quercetin glycoside hyperoside was the major polyphenolic compound ( $30.3 \%$ of total polyphenols content) in the peel of all apple cultivars investigated and can be regarded as a marker for apple peel. Looking at the polyphenol profile in the flesh, the phenolic acids $(43.0 \%)$ and the flavanols $(41.1 \%)$ were the predominant groups, followed by the dihydrochalcon phloridzin $(14.0 \%)$. The flavonols were missing in the flesh. The apple peel and flesh differed distinctly in the phenolic glycoside composition (Tables 2 and 3). The flesh contained the phloretin glycoside phloridzin, whereas peel possessed both phloridzin and quercetin glycosides [25]. Within the phenolic acids, chlorogenic acid was the major compound in the peel $(6.3 \pm 3.310 \mathrm{mg} / 100 \mathrm{~g})$ and in the flesh $(5.0 \pm 3.0 \mathrm{mg} / 100 \mathrm{~g})$.

As described by Guyot et al., (1998), the phenolic acid content decreased from the peel to the flesh [10]. A total of six flavanols could be quantified in both peel $(36.3 \pm 11.7 \mathrm{mg} / 100 \mathrm{~g})$ and flesh $(9.6 \pm 5.0 \mathrm{mg} / 100 \mathrm{~g})$, but their concentrations in the flesh were much lower than in the peel. In addition to $(+)$-catechin and (-)-epicatechin, the procyanidin isomers B1, B2, C1 and A2 were identified, even if they were not detectable in all apple cultivars. In previous studies, the flavanols, especially the procyanidins, were the major class of apple polyphenols in both flesh and peel, representing more than $80 \%$ of the total polyphenol content (HPLC data) $[8,11,13,23,28]$. However, the content and percentage of flavanols obtained in this study were lower than the quantities reported in other research. One possible reason for this may be the crushing of the apples without adding an antioxidant, like ascorbic acid. Flavanol monomers and procyanidins are good substrates for polyphenol oxidase and are directly involved in enzymatic oxidation, occurring when apples are crushed [10].

In addition to the determination of polyphenolic compounds, the vitamin $C$ content of the apples was analysed. The vitamin $C$ content in the peel ranged from $99.2 \pm 10.0$ (Granny Smith) to $300.9 \pm 10.8$ (Ontario) $\mathrm{mg} / 100 \mathrm{~g}$, and in the flesh from $50.4 \pm 2.4$ (Golden Delicious) to $143.4 \pm 1.8$ (Ontario) $\mathrm{mg} / 100 \mathrm{~g}$. The vitamin $C$ results are similar to other investigations $[13,30,31]$, but tended to be higher, which may be due to our method. In the spectrophotometric method with DNP reagent, used in this research, the total content of vitamin $C$ was analysed, i.e., the content of ascorbic acid and dehydroascorbic acid present in the apples. The vitamin $C$ concentration significantly correlated with the polyphenol content, in both flesh and peel $(r=0.515 ; p<0.001$ and $r=0.736$; $p<0.001$, respectively). Therefore, as with the polyphenols, the content of vitamin $C$ in the peel was higher (1.5- to 3.3-fold greater), compared to the flesh. A possible reason for the higher content of polyphenols and vitamin $C$ in the peel, compared to the flesh, might be the barrier function of the peel against external biotic and abiotic stress, to which apples are often exposed [32]. Thus, a higher concentration of antioxidants appears to be useful in the peel.

\subsection{Antioxidant Capacity (AOC)}

As shown in Tables 2 and 3, peel extracts had a stronger AOC than the flesh extracts, being comparable to studies previously reported $[3,4,27,33,34]$. The apple cultivar Oldenburger possessed the significantly highest AOC in the peel, and Jonathan in the flesh. The cultivars Golden Delicious and Braeburn had the significantly lowest AOC measured by all methods, in both peel 
and flesh. The total polyphenol content (HPLC data) significantly correlated with the values of the AOC results (TPC: 0.891; H-TEAC: 0.886; H-ORAC: 0.908; $p<0.001$ ). The significant correlation between the vitamin C content and the AOC results (TPC: 0.867; H-TEAC: 0.861; H-ORAC: 0.883; $p<0.001$ ) was lower compared to the polyphenols and suggest that the polyphenols have a more significant contribution to the AOC. The best correlation was found between the total polyphenols (HPLC data) and the H-ORAC results $(r=0.908 ; p<0.001)$. The reaction mechanism of the ORAC assay is based on free peroxyl radicals, which are commonly found in the human body, making the reaction biologically relevant [34]. The H-ORAC values of the peel extracts showed the best positive linear correlation with the total flavanols $(r=0.767 ; p<0.001)$ in the decreasing order of $(-)$-epicatechin $>$ procyanidin $\mathrm{C} 1>(+)$-catechin $>$ procyanidin $\mathrm{A} 2$. Next to the flavanols, the total flavonols significantly correlated with the H-ORAC results $(r=0.651 ; p<0.001)$, but the flavanols had an even better linear correlation. Similar observations for the flavanols were found in the flesh extracts $(r=0.784 ; p<0.001)$, with some differences in the order: $(+)$-catechin $>(-)$-epicatechin $>$ procyanidin A2 $>$ procyanidin B2. These results show that the flavanols are major contributors to the AOC (H-ORAC), in both peel and flesh.

\subsection{Relative Contribution to AOC}

To indicate the relative contribution of single antioxidants to the AOC of each apple sample, the relative antioxidant activities (RAA) of the 20 polyphenolic compounds and vitamin $C$ were calculated. The RAA resulted from the quotient of the molar AOA value of the H-ORAC assay of the corresponding polyphenol standard, and the molar concentration at which the H-ORAC was obtained.

$$
\mathrm{RAA}=\mathrm{AOA} / \mathrm{C}
$$

The RAA of the polyphenols showed the following order: procyanidin B1 (10.4) and procyanidin $\mathrm{C} 1(10,4)>$ procyanidin $\mathrm{B} 2(9.6)>$ rutin trihydrate $(9.1)>$ phloridzin dihydrate $(8.7)>$ reynoutrin $(8.6)>$ hyperoside $(7.9)>$ isoquercitrin $(7.2)>$ quercetin $(6.8)>$ avicularin $(6.7)>$ quercitrin $(6.6)>$ procyanidin A2 (6.0) > (-)-epicatechin (5.0) > p-coumaric acid (4.9) and (+)-catechin (4.9) > chlorogenic acid (4.7) > protocatechuic acid (4.3) > caffeic acid (4.0) > ferulic acid (2.9) > gallic acid (1.7) > vitamin C (0.9).

The relative contribution of a single compound to the AOC of apple extracts was obtained as follows:

$$
\text { contribution [\%] }=\mathrm{C}_{\mathrm{HPLC}} \times(\mathrm{RAA} / \mathrm{AOC}) \times 100
$$

$\mathrm{C}_{\text {HPLC }}$ is the molar concentration of an individual compound, determined by HPLC analysis, RAA is the RAA value of the corresponding standard and AOC is the H-ORAC value of the apple sample. The total relative contribution is a sum of all calculated relative contribution values of the polyphenols determined in each apple sample.

Vitamin $C$ has been considered to be one of the most prevalent antioxidant components in apples. However, as Lee et al. (2003) reported, dietary polyphenols have much stronger antioxidant activities than vitamin C [7], being confirmed by our investigations. A comparison of the measured AOC with the calculated H-ORAC value (sum of contributions of polyphenols) showed that only $26.1 \%$ (between $15.4 \%$ and $37.4 \%$ ) of the AOC of the apple peel and $15.9 \%$ (between $9.3 \%$ and $25.3 \%$ ) of the AOC of the apple flesh were due to the compounds analysed (Figure 1).

All results calculated were smaller than those of the values measured, suggesting unquantified polyphenolic compounds and possible synergisms and/or antagonisms among the polyphenols [3,7]. The values calculated were smaller than those reported by other authors, due to possibly different apple cultivars, AOC assays and methods for extraction and quantification of polyphenolic compounds $[3,35,36]$. 


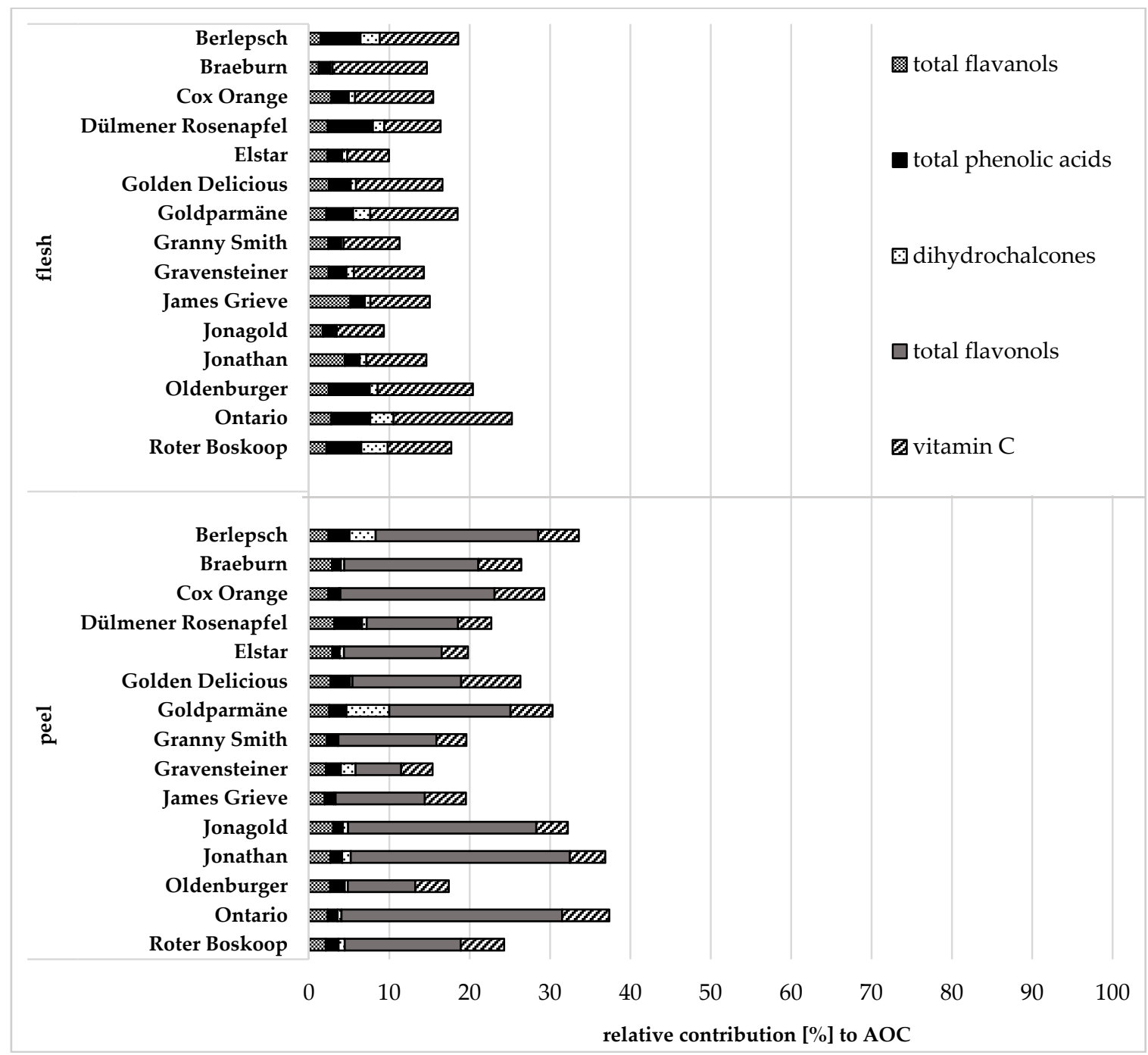

Figure 1. Relative contributions of the main polyphenol groups and vitamin $C$ to the antioxidant capacity (AOC) of different apple cultivars in flesh and peel, calculated using H-ORAC results; H-ORAC: hydrophilic oxygen radical absorbance capacity.

Hyperoside had the highest contribution (6.8\%) to the AOC in the peel, followed by quercitrin $(2.1 \%)$ and avicularin $(2.0 \%)$, whereas in the flesh, phloridzin and chlorogenic acid $(1.2 \%)$ contributed the most, followed by caffeic acid $(1.0 \%)$ and procyanidin A2 $(0.8 \%)$. Considering the content of each polyphenolic compound, the total polyphenols had an average contribution of $21.2 \%(11.5-32.5 \%)$ to the AOC in the peel and of $6.8 \%(2.9-10.5 \%)$ to AOC in the flesh. In the apple peel, an average of $15.9 \%$ of the calculated AOC was due to the flavonols, $2.5 \%$ due to the flavanols, $1.7 \%$ due to the phenolic acids and $1.1 \%$ due to the dihydrochalcone phloridzin (Figure 1). Of the three polyphenolic groups identified in the flesh, the total phenolic acids provided $3.0 \%$, followed by the total flavanols $(2.6 \%)$ and the dihydrochalcone phloridzin (1.2\%) (Figure 1). These results are in agreement with other publications, showing a strong AOA for flavanols and flavonols, being thus main contributors to the AOC of apples $[3,7,8,36,37]$. In addition to the polyphenols, vitamin C contributed to the AOC of peel $(4.9 \%)$ and flesh $(9.1 \%)$. These results clearly indicate that in the peel flavonols rather than vitamin $\mathrm{C}$ made the major contribution to AOC of apples, whereas in the flesh, vitamin $\mathrm{C}$ provided the highest contribution. 


\subsection{Comparison of Old and New Apple Cultivars}

In the present study, the extracts of flesh and peel of old apple cultivars $(n=10)$ and new apple cultivars $(n=5)$ were analysed in terms of their polyphenolic profiles, vitamin C content and AOC. The flesh of old cultivars had significantly higher content of polyphenolic compounds (HPLC data) and vitamin $C$, compared to the flesh of new cultivars, which led also to a higher AOC in TPC, H-TEAC and H-ORAC assays for the old ones. In contrast to the flesh, the polyphenolic content and the AOC of the apple peel did not differ between old and new cultivars, whereas the vitamin $C$ content was significantly higher in the peel of old cultivars. As shown in Table 4, the polyphenolic profile of the new apple cultivars was characterised by a lower content of total flavanols (flesh) and total phenolic acids (flesh and peel) and a lower content of phloridzin (flesh and peel), compared to the old ones. The lower content of flavanols and phloridzin resulted in a lower AOC in the new apple cultivars, because monomeric and oligomeric flavan-3-ols and phloridzin are strong antioxidants with high AOAs.

Table 4. Comparison of content of vitamin C, phenolic compounds and antioxidant capacity results between old apple cultivars $(n=10)$ and new apple cultivars $(n=5)$.

\begin{tabular}{|c|c|c|c|c|c|c|}
\hline & \multicolumn{3}{|c|}{ Apple Flesh } & \multicolumn{3}{|c|}{ Apple Peel } \\
\hline & Old Cultivars & New Cultivars & $p$ & Old Cultivars & New Cultivars & $p$ \\
\hline ascorbic acid & $102.6 \pm 19.3$ & $68.5 \pm 23.7$ & $<0.001$ & $203.5 \pm 50.5$ & $162.9 \pm 45.9$ & 0.012 \\
\hline procyanidin B1 & $1.0 \pm 1.9$ & $1.0 \pm 0.1$ & 0.081 & $1.9 \pm 1.6$ & n.d. & - \\
\hline$(+)$-catechin & $1.5 \pm 1.2$ & $1.1 \pm 0.9$ & 0.351 & $5.1 \pm 3.0$ & $5.4 \pm 3.0$ & 0.745 \\
\hline procyanidin B2 & $1.9 \pm 0.5$ & $1.6 \pm 0.3$ & 0.061 & $7.1 \pm 1.5$ & $7.4 \pm 1.4$ & 0.427 \\
\hline procyanidin C1 & $1.5 \pm 0.2$ & n.d. & - & $6.7 \pm 1.2$ & $7.8 \pm 1.1$ & 0.016 \\
\hline (-)-epicatechin & $1.7 \pm 1.2$ & $1.0 \pm 0.7$ & 0.034 & $8.8 \pm 4.9$ & $10.1 \pm 7.2$ & 0.543 \\
\hline procyanidin A2 & $4.8 \pm 2.6$ & $2.5 \pm 1.2$ & $<0.001$ & $7.8 \pm 2.9$ & $7.7 \pm 3.4$ & 0.855 \\
\hline total flavanols & $11.2 \pm 5.2$ & $6.4 \pm 2.5$ & $<0.001$ & $36.1 \pm 8.8$ & $36.8 \pm 16.5$ & 0.883 \\
\hline gallic acid & $1.8 \pm 0.2$ & $1.6 \pm 0.2$ & 0.054 & $4.6 \pm 1.0$ & $3.9 \pm 0.3$ & 0.001 \\
\hline protocatechuic acid & $0.1 \pm 0.1$ & $0.1 \pm 0.0$ & 0.005 & $2.0 \pm 0.8$ & $1.3 \pm 0.6$ & 0.012 \\
\hline chlorogenic acid & $6.4 \pm 2.7$ & $2.1 \pm 0.8$ & $<0.001$ & $6.7 \pm 4.0$ & $5.6 \pm 0.7$ & 0.159 \\
\hline caffeic acid & $3.3 \pm 2.4$ & $0.8 \pm 0.5$ & $<0.001$ & $4.6 \pm 3.7$ & $0.8 \pm 0.5$ & $<0.001$ \\
\hline p-coumaric acid & $0.7 \pm 0.1$ & $0.5 \pm 0.1$ & $<0.001$ & $2.8 \pm 1.3$ & $1.8 \pm 0.4$ & $<0.001$ \\
\hline ferulic acid & $0.2 \pm 0.1$ & $0.1 \pm 0.1$ & 0.003 & $1.3 \pm 0.6$ & $0.9 \pm 0.4$ & 0.007 \\
\hline total phenolic acids & $12.5 \pm 4.9$ & $5.2 \pm 1.3$ & $<0.001$ & $22.0 \pm 7.7$ & $14.3 \pm 2.1$ & $<0.001$ \\
\hline phloridzin & $5.0 \pm 3.1$ & $1.1 \pm 0.7$ & $<0.001$ & $16.6 \pm 18.7$ & $4.8 \pm 3.5$ & 0.002 \\
\hline hyperoside & n.d. & n.d. & - & $92.2 \pm 55.8$ & $84.2 \pm 57.1$ & 0.657 \\
\hline isoquercitrin & n.d. & n.d. & - & $17.8 \pm 11.9$ & $16.6 \pm 8.6$ & 0.716 \\
\hline rutin & n.d. & n.d. & - & $7.1 \pm 7.9$ & $5.4 \pm 3.3$ & 0.319 \\
\hline reynoutrin & n.d. & n.d. & - & $19.0 \pm 11.5$ & $17.0 \pm 7.6$ & 0.550 \\
\hline avicularin & n.d. & n.d. & - & $30.6 \pm 15.2$ & $21.4 \pm 8.4$ & 0.035 \\
\hline quercitrin & n.d. & n.d. & - & $29.8 \pm 20.3$ & $25.4 \pm 13.1$ & 0.455 \\
\hline quercetin & n.d. & n.d. & - & $15.5 \pm 7.9$ & $13.4 \pm 5.2$ & 0.366 \\
\hline total flavonols & n.d. & n.d. & - & $212.1 \pm 112.3$ & $183.5 \pm 99.6$ & 0.410 \\
\hline total polyphenols & $28.7 \pm 7.4$ & $12.6 \pm 4.4$ & $<0.001$ & $286.8 \pm 118.8$ & $239.4 \pm 118.6$ & 0.214 \\
\hline TPC & $257.0 \pm 56.7$ & $179.5 \pm 52.3$ & $<0.001$ & $995.9 \pm 281.6$ & $914.7 \pm 331.3$ & 0.163 \\
\hline TEAC & $1.5 \pm 0.4$ & $1.0 \pm 0.3$ & $<0.001$ & $6.9 \pm 2.8$ & $5.9 \pm 2.7$ & 0.051 \\
\hline ORAC & $5.7 \pm 1.3$ & $4.6 \pm 1.6$ & $<0.001$ & $21.4 \pm 5.4$ & $19.2 \pm 7.8$ & 0.060 \\
\hline
\end{tabular}

$p$-Values represent results from unpaired $t$-test $(p<0.05$; significant values are shown in bold); n.d.: not detected; TPC: total phenolic content; TEAC: trolox equivalent antioxidant capacity; ORAC: oxygen radical antioxidant capacity; single compounds and total concentrations in $\mathrm{mg} / 100 \mathrm{~g}$ freeze dried material; TPC in mg GAE/100 g freeze dried material; TEAC and ORAC in mmol TE/100 g freeze dried material; GAE: gallic acid equivalents; TE: trolox equivalents.

Phenolic acids and flavanols are responsible for an astringent taste and a rapid enzymatic browning of apples [38]. Since consumers prefer sweet-flavoured and low enzymatic browning apples, the content of phenolic acids and flavanols decreased by breeding new apple cultivars. New apple cultivars tend to be genetically impoverished because they are almost entirely due to six similar strain varieties, but old cultivars have a higher vitality [39]. Presumably, the flesh of old cultivars contains 
higher levels of polyphenolic compounds, vitamin C and AOC due to species diversity. Vrhovsek et al., (2004) also showed that old cultivars (whole fruit, without separation into peel and flesh) have a higher average content of total polyphenols and, in particular, of flavanols, compared to new cultivars [13]. A reason why there are no differences in the peel between old and new cultivars may be the protective function of antioxidants, like polyphenolic compounds, in the peel; thus, they are necessary ingredients to counter biotic and abiotic factors.

\section{Conclusions}

The results of this research clearly indicated that flavonols, rather than vitamin $C$, make the major contribution to AOC in apple peel, whereas in the flesh, vitamin C provides the highest contribution next to the flavanols. The flesh of old apple cultivars had a higher content of polyphenolic compounds and vitamin $C$, resulting in a higher AOC compared to new apple cultivars. For this reason, it is recommended to include preferably old apple cultivars, such as Jonathan, Ontario and Oldenburger, in the daily diet. Additionally, it is advisable to consume the apple with peel, due to its higher polyphenolic content and stronger AOC. Both aspects can help to increase the polyphenol intake and the AOC within the daily diet.

Supplementary Materials: The following are available online at www.mdpi.com/2076-3921/7/1/20/s1, Table S1: Calibration characteristics and limits of detection (LOD) and limits of quantification (LOQ) of reference compounds in HPLC-DAD.

Author Contributions: Josephine Kschonsek and Volker Böhm conceived and designed the experiments; Josephine Kschonsek performed the experiments; Josephine Kschonsek, Theresa Wolfram and Annette Stöckel analysed the data; Josephine Kschonsek wrote the paper; Josephine Kschonsek and Volker Böhm critically read the manuscript and corrected it. All authors approved the final manuscript.

Conflicts of Interest: The authors declare no existing conflict of interest.

\section{References}

1. Hyson, D.A. A comprehensive review of apples and apple components and their relationship to human health. Adv. Nutr. 2011, 2, 408-420. [CrossRef] [PubMed]

2. Scalbert, A.; Morand, C.; Manach, C.; Rémésy, C. Absorption and metabolism of polyphenols in the gut and impact on health. Biomed. Pharmacother. 2002, 56, 276-282. [CrossRef]

3. Tsao, R.; Yang, R.; Xie, S.; Sockovie, E.; Khanizadeh, S. Which polyphenolic compounds contribute to the total antioxidant activities of apple? J. Agric. Food. Chem. 2005, 53, 4989-4995. [CrossRef] [PubMed]

4. Wolfe, K.; Wu, X.; Liu, R.H. Antioxidant activity of apple peels. J. Agric. Food. Chem. 2003, 51, 609-614. [CrossRef] [PubMed]

5. Bundesministerium für Ernährung und Landwirtschaft. Pressemitteilung Nr. 232, 2013. Available online: http:/ / www.bmel.de/SharedDocs/Pressemitteilungen/2013/232-Zahl-der-Woche-Obstverbrauch. html?nn=312878 (accessed on 25 April 2017).

6. Han, X.; Shen, T.; Lou, H. Dietary polyphenols and their biological significance. Int. J. Mol. Sci. 2007, 8, 950-988. [CrossRef]

7. Lee, K.W.; Kim, Y.J.; Kim, D.; Lee, H.J.; Lee, C.Y. Major phenolics in apple and their contribution to the total antioxidant capacity. J. Agric. Food. Chem. 2003, 51, 6516-6520. [CrossRef] [PubMed]

8. Wojdyło, A.; Oszmiański, J.; Laskowski, P. Polyphenolic compounds and antioxidant activity of new and old apple varieties. J. Agric. Food. Chem. 2008, 56, 6520-6530. [CrossRef] [PubMed]

9. Łata, B.; Trampczynskab, A.; Paczesnaa, J. Cultivar variation in apple peel and whole fruit phenolic composition. Sci. Hortic. 2009, 121, 176-181. [CrossRef]

10. Guyot, S.; Marnet, N.; Djamel, L.; Sanoner, P.; Drilleau, J.F. Reversed-phase HPLC following thiolysis for quantitative estimation and characterization of the four main classes of phenolic compounds in different tissue zones of a French cider apple variety (Malus domestica Var. Kermerrien). J. Agric. Food Chem. 1998, 46, 1698-1705. [CrossRef]

11. Tsao, R.; Yang, R.; Young, J.C.; Zhu, H. Polyphenolic profiles in eight apple cultivars using High-Performance Liquid Chromatography (HPLC). J. Agric. Food. Chem. 2003, 51, 6347-6353. [CrossRef] [PubMed] 
12. Van der Sluis, A.A.; Dekker, M.; de Jager, A.; Jongen, W. Activity and concentration of polyphenolic antioxidants in apple: Effect of cultivar, harvest year, and storage conditions. J. Agric. Food. Chem. 2001, 49, 3606-3613. [CrossRef] [PubMed]

13. Vrhovsek, U.; Rigo, A.; Tonon, D.; Mattivi, F. Quantitation of polyphenols in different apple varieties. J. Agric. Food. Chem. 2004, 52, 6532-6538. [CrossRef] [PubMed]

14. Bitsch, R.; Netzel, M.; Frank, T.; Strass, G.; Bitsch, I. Bioavailability and biokinetics of anthocyanins from red grape juice and red wine. J. Biomed. Biotechnol. 2004, 5, 293-298. [CrossRef] [PubMed]

15. Liaudanskas, M.; Viškelis, P.; Jakštas, V.; Raudonis, R.; Kviklys, D.; Milašius, A.; Janulis, V. Application of an optimized HPLC method for the detection of various phenolic compounds in apples from Lithuanian cultivars. J. Chem. 2014, 2014, 1-10. [CrossRef]

16. Abad-García, B.; Berrueta, L.A.; López-Márquez, D.M.; Crespo-Ferrer, I.; Gallo, B.; Vicente, F. Optimization and validation of a methodology based on solvent extraction and liquid chromatography for the simultaneous determination of several polyphenolic families in fruit juices. J. Chromatogr. A 2007, 1154, 87-96. [CrossRef] [PubMed]

17. Müller, L.; Gnoyke, S.; Popken, A.M.; Böhm, V. Antioxidant capacity and related parameters of different fruit formulations. LWT-Food Sci. Technol. 2010, 43, 992-999. [CrossRef]

18. Singleton, V.L.; Rossi, J.A. Colorimetry of total phenolics with phosphomolybdic-phosphotungstic acid reagents. Am. J. Enol. Vitic. 1965, 16, 144-158.

19. Re, R.; Pellegrini, N.; Proteggente, A.; Pannala, A.; Yang, M.; Rice-Evans, C. Antioxidant activity applying an improved ABTS radical cation decolorization assay. Free Radic. Biol. Med. 1999, 26, 1231-1237. [CrossRef]

20. Ou, B.; Hampsch-Woodill, M.; Prior, R.L. Development and validation of an improved oxygen radical absorbance capacity assay using fluorescein as the fluorescent probe. J. Agric. Food. Chem. 2001, 49, 4619-4626. [CrossRef] [PubMed]

21. Al-Duais, M.; Müller, L.; Böhm, V.; Jetschke, G. Antioxidant capacity and total phenolics of Cyphostemma digitatum before and after processing: Use of different assays. Eur. Food. Res. Technol. 2009, 228, 813-821. [CrossRef]

22. Petkovsek, M.M.; Stampar, F.; Veberic, R. Parameters of inner quality of the apple scab resistant and susceptible apple cultivars (Malus domestica Borkh). Sci. Hortic. 2007, 114, 37-44. [CrossRef]

23. Escarpa, A.; González, M.C. High-performance liquid chromatography with diode-array detection for the determination of phenolic compounds in peel and pulp from different apple varieties. J. Chromatogr. A 1998, 823, 331-337. [CrossRef]

24. Napolitano, A.; Cascone, A.; Graziani, G.; Ferracane, R.; Scalfi, L.; Di Vaio, C.; Ritieni, A.; Fogliano, V. Influence of variety and storage on the polyphenol composition of apple flesh. J. Agric. Food Chem. 2004, 52, 6526-6531. [CrossRef] [PubMed]

25. Oleszek, W.; Lee, C.Y.; Jaworski, A.W.; Price, K.R. Identification of some phenolic compounds in apples. J. Agric. Food Chem. 1988, 36, 430-432. [CrossRef]

26. Wach, A.; Pyrzynska, K.; Biesaga, M. Quercetin content in some food and herbal samples. Food Chem. 2007, 100, 699-704. [CrossRef]

27. Burda, S.; Oleszek, W.; Lee, C.Y. Phenolic compounds and their changes in apples during maturation and cold storage. J. Agric. Food. Chem. 1990, 38, 945-948. [CrossRef]

28. Khanizadeh, S.; Tsao, R.; Rekika, D.; Yang, R.; Charles, M.T.; Rupasinghe, V. Polyphenol composition and total antioxidant capacity of selected apple genotypes for processing. J. Food Compos. Anal. 2008, 21, 396-401. [CrossRef]

29. Raudone, L.; Raudonis, R.; Liaudanskas, M.; Viskelis, J.; Pukalskas, A.; Janulis, V. Phenolic profiles and contribution of individual compounds to antioxidant activity of apple powders. J. Food Sci. 2016, 81, C1055-C1061. [CrossRef] [PubMed]

30. Planchon, V.; Lateur, M.; Dupont, P.; Lognay, G. Ascorbic acid level of Belgian apple genetic resources. Sci. Hortic. 2004, 100, 51-61. [CrossRef]

31. Pissard, A.; Pierna, J.A.F.; Baeten, V.; Sinnaeve, G.; Lognay, G.; Mouteau, A.; Dupont, P.; Rondia, A.; Lateur, M. Non-destructive measurement of vitamin $C$, total polyphenol and sugar content in apples using near-infrared spectroscopy. J. Sci. Food Agric. 2013, 93, 238-244. [CrossRef] [PubMed]

32. Łata, B.; Tomala, K. Apple peel as a contributor to whole fruit quantity of potentially healthful bioactive compounds. Cultivar and year implication. J. Agric. Food Chem. 2007, 55, 10795-10802. [CrossRef] [PubMed] 
33. Drogoudi, P.D.; Michailidis, Z.; Pantelidis, G. Peel and flesh antioxidant content and harvest quality characteristics of seven apple cultivars. Sci. Hortic. 2008, 115, 149-153. [CrossRef]

34. Giomaro, G.; Karioti, A.; Bilia, A.R.; Bucchini, A.; Giamperi, L.; Ricci, D.; Fraternale, D. Polyphenols profile and antioxidant activity of skin and pulp of a rare apple from Marche region (Italy). Chem. Cent. J. 2014, 8, 45. [CrossRef] [PubMed]

35. Van der Sluis, A.A.; Dekker, M.; Skrede, G.; Jongen, W.M.F. Activity and concentration of polyphenolic antioxidants in apple juice. 1. Effect of existing production methods. J. Agric. Food. Chem. 2002, 50, 7211-7219. [CrossRef] [PubMed]

36. Chinnici, F.; Bendini, A.; Gaiani, A.; Riponi, C. Radical scavening activities of pees and pulps from cv. Golden Delicious apples as related to their phenolic composition. J. Agric. Food. Chem. 2004, 52, 4684-4689. [CrossRef] [PubMed]

37. Stracke, A.B.; Rüfer, C.E.; Bub, A.; Weibel, F.P.; Kunz, C.; Watzl, B. Three-year comparison of the polyphenol contens and antioxidant capacities in organically and conventionally produced apples (Malus domestica Bork. Cultivar Golden Delicious). J. Agric. Food Chem. 2009, 57, 4598-4605. [CrossRef] [PubMed]

38. Renard, C.M.; Dupont, N.; Guillermin, P. Concentrations and characteristics of procyanidins and other phenolics in apples during fruit growth. Phytochemistry 2007, 68, 1128-1138. [CrossRef] [PubMed]

39. Bannier, H. Moderne Apfelzüchtung: Genetische Verarmung und Tendenzen zur Inzucht. Vitalitätsverluste erst bei Verzicht auf Fungizideinsatz sichtbar. Erwerbs-Obstbau 2011, 52, 85-110. [CrossRef]

(C) 2018 by the authors. Licensee MDPI, Basel, Switzerland. This article is an open access article distributed under the terms and conditions of the Creative Commons Attribution (CC BY) license (http://creativecommons.org/licenses/by/4.0/). 